\title{
Performed Observation Result Baseline Indicator
}

National Cancer Institute

\section{Source}

National Cancer Institute. Performed Observation Result Baseline Indicator. NCI

Thesaurus. Code C93936.

Specifies whether the result is a starting point to which other results may be compared. 